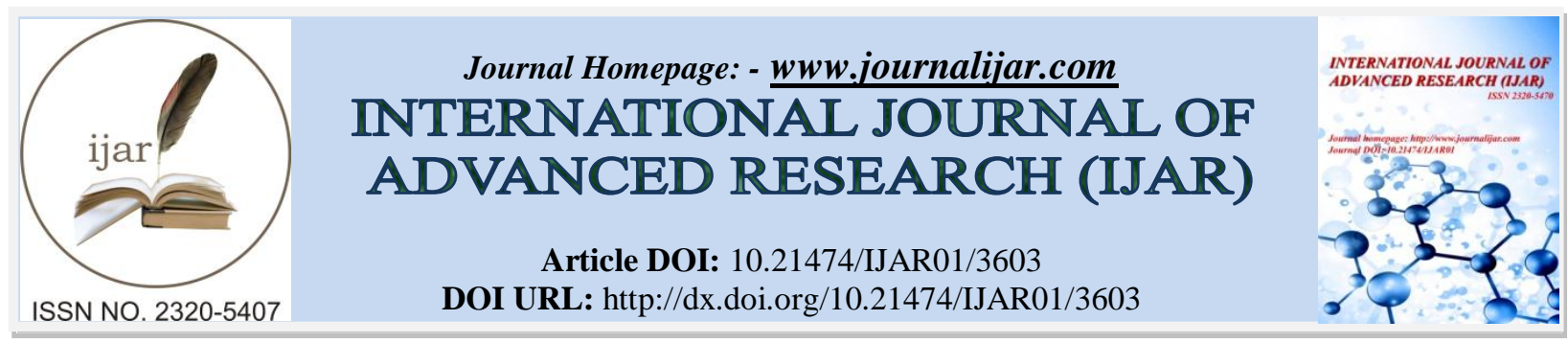

RESEARCH ARTICLE

\title{
A COMPERATIVE STUDY ON THE PERFORMANCE OF THE STUDENTS IN MATHEMATICS AND SOCIAL SCIENCE.
}

Debojit Mitra.

Mathematics Teacher, Doom Dooma Bangiya Vidyalaya, Doom Dooma, Assam, India.

\section{Manuscript Info}

Manuscript History

Received: 06 January 2017

Final Accepted: 05 February 2017

Published: March 2017

\section{Abstract}

\section{Introduction:-}

Being a Mathematics Teacher in a Senior Secondary School of our locality, I personally observe the fact that students of Secondary Sections pay less attention as well as they are less interested in the Subject General Mathematics in comparison to other Subjects. They have a fear in mind about Mathematics and so always hesitate to apply their intellect in solving sums. As the subject itself can't produce any interest among the students unlike to literature, history, Social Science etc from which the students get something interesting going through the lessons and hence they pay less attention to that subject.

To make Mathematics interesting, I myself have tried to help them learn with the help of different models which I have made myself of angles, triangles, quadrilaterals, geo-board, Models of Venn diagrams with simple things like ball pens, riffles, straw pipes, Card-boards bangles and plywood etc. The result I got is very interesting. The students get interested in Practical Classes but still they are lagged behind in theoretical knowledge. Taking this matter as a subject of my project, I have collected the marks obtained in Annual Examination of last two years of the students of Class - IX and Class - X in mathematics and Social Science and a thorough Statistical Study has been done.

\section{Methodology:}

A statistical survey has been performed among the students of Class - IX and X in a High School in our locality and their marks in General mathematics and Social Science in Annual Examination for 2015 and 2016 respectively and the marks obtained by them have been tabulated in grouped data and the result has been thoroughly studied to find the fact if they are lagged behind in Mathematics in Comparison to Social Science. The marks obtained by the students in General Mathematics and Social Science is tabulated in grouped data and the results are shown graphically. 
Results Of Class Ix In Mathematics And Social Science, 2015.

Only marks in theory (Full marks $=\mathbf{8 0}$ ) is considered here. 20 marks in practical is not considered in tabulation.

\begin{tabular}{|c|c|c|}
\hline \multirow{2}{*}{$\begin{array}{c}\text { Class Interval } \\
\text { (Marks obtained) }\end{array}$} & \multicolumn{2}{|c|}{ Frequency (Number of students) } \\
\hline & General Mathematics & Social Science \\
\hline $0-10$ & 21 & 05 \\
\hline $10-20$ & 24 & 12 \\
\hline $20-30$ & 29 & 31 \\
\hline $30-40$ & 09 & 20 \\
\hline $40-50$ & 02 & 12 \\
\hline $50-60$ & 01 & 01 \\
\hline $60-70$ & 01 & 01 \\
\hline $70-80$ & 02 & 07 \\
\hline To & 89 & 89 \\
\hline
\end{tabular}

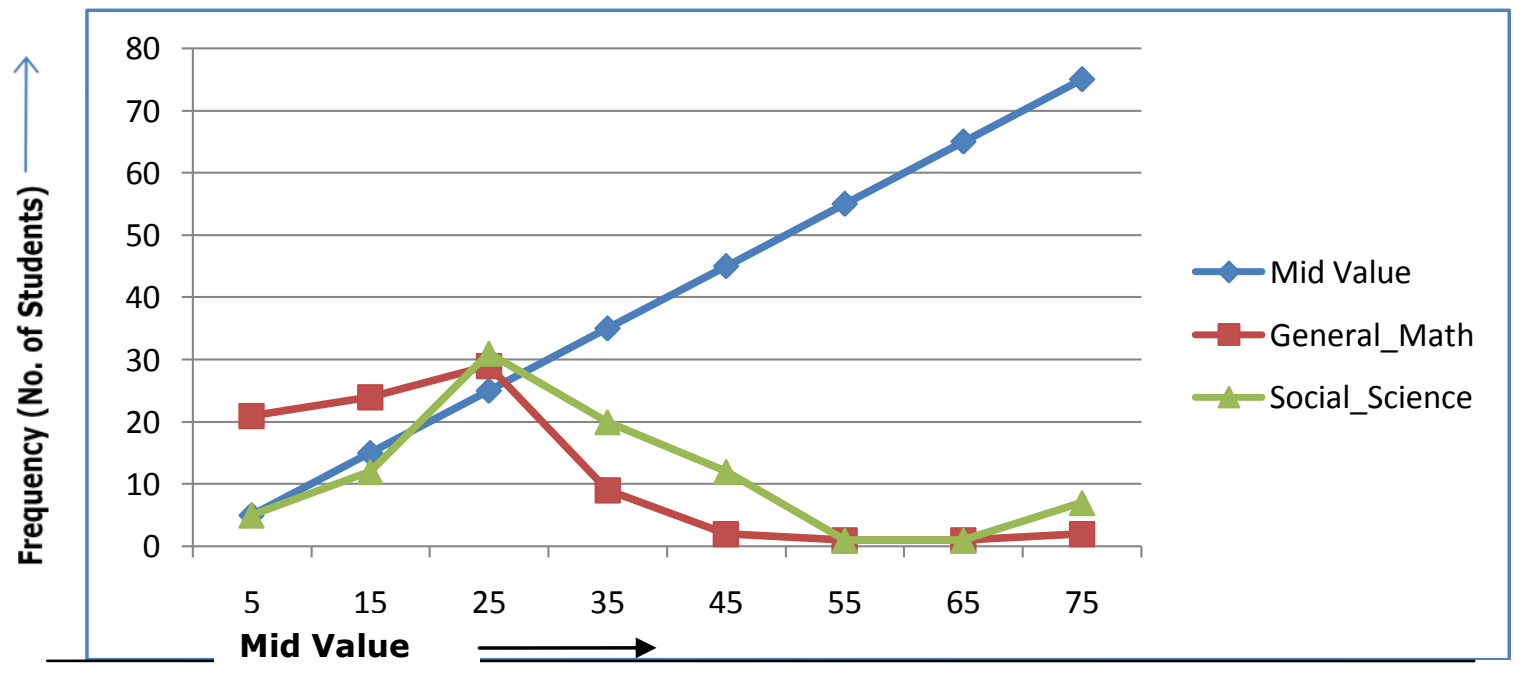

Results of Class X in Mathematics and Social Science, 2015.

Only marks in theory (Full marks $=80$ ) is considered here. 20 marks in practical is not considered in tabulation.

\begin{tabular}{|c|c|c|}
\hline \multirow{2}{*}{$\begin{array}{c}\text { Class Interval } \\
\text { (Marks obtained) }\end{array}$} & \multicolumn{2}{|c|}{ Frequency (Number of students) } \\
\hline & General Mathematics & Social Science \\
\hline $0-10$ & 5 & 00 \\
\hline $10-20$ & 9 & 05 \\
\hline $20-30$ & 14 & 04 \\
\hline $30-40$ & 07 & 15 \\
\hline $40-50$ & 08 & 10 \\
\hline $50-60$ & 02 & 06 \\
\hline $60-70$ & 01 & 03 \\
\hline $70-80$ & 01 & 04 \\
\hline To & 47 & 47 \\
\hline
\end{tabular}




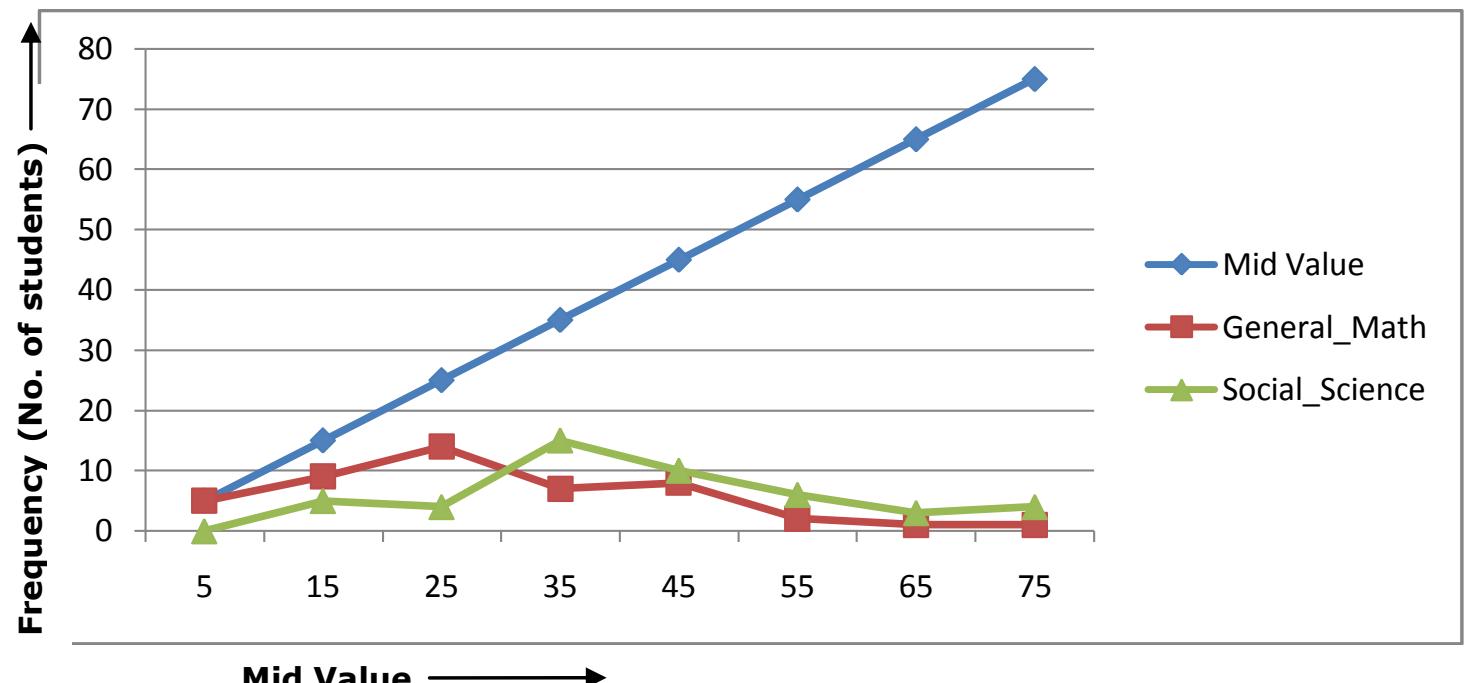

Results of Class IX in Mathematics and Social Science, 2016:-

Only marks in theory (Full marks $=80$ ) is considered here. 20 marks in practical is not considered in tabulation.

\begin{tabular}{|c|c|c|}
\hline \multirow{2}{*}{$\begin{array}{c}\text { Class Interval } \\
\text { (Marks obtained) }\end{array}$} & \multicolumn{2}{|c|}{ Frequency (Number of students) } \\
\hline & General Mathematics & Social Science \\
\hline $0-10$ & 13 & 00 \\
\hline $10-20$ & 10 & 02 \\
\hline $20-30$ & 29 & 18 \\
\hline $30-40$ & 18 & 25 \\
\hline $40-50$ & 07 & 15 \\
\hline $50-60$ & 01 & 05 \\
\hline $60-70$ & 01 & 10 \\
\hline \multirow[t]{2}{*}{$70-80$} & 01 & 05 \\
\hline & 80 & 80 \\
\hline
\end{tabular}

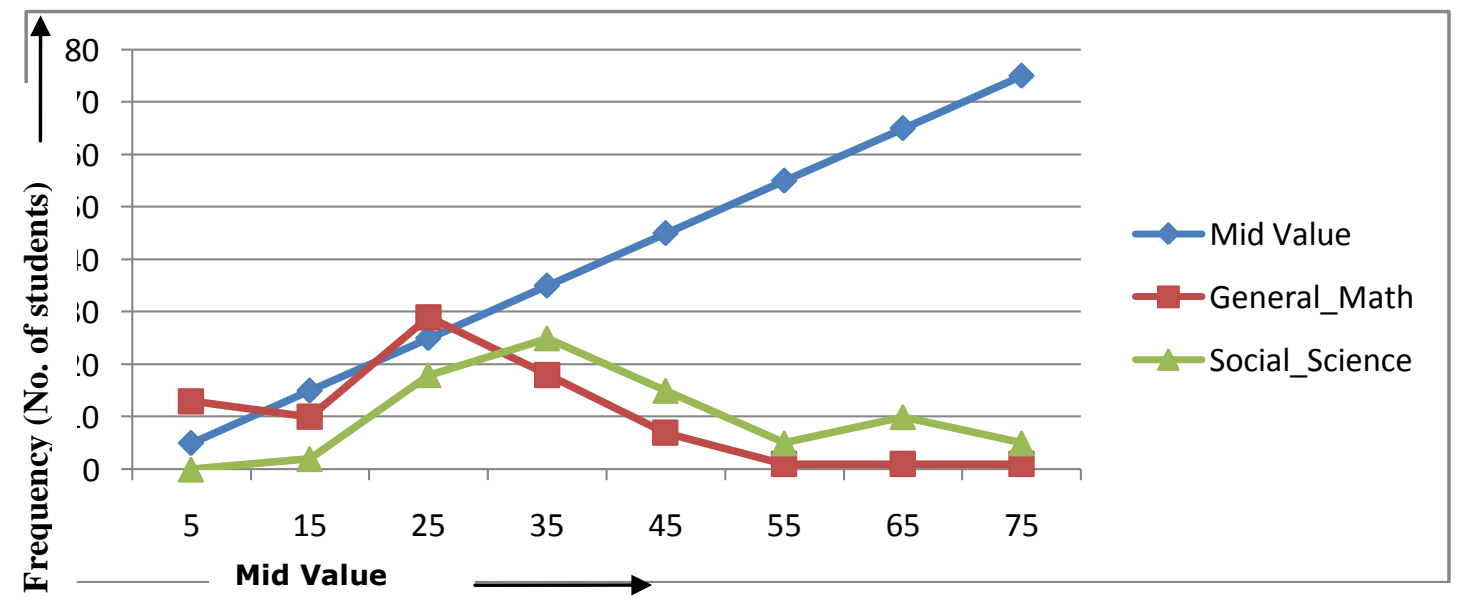


Results of Class X in Mathematics and Social Science, 2016:-

Only marks in theory (Full marks $=80$ ) is considered here. 20 marks in practical is not considered in tabulation.

\begin{tabular}{|c|c|c|}
\hline \multirow{2}{*}{$\begin{array}{c}\text { Class Interval } \\
\text { (Marks obtained) }\end{array}$} & \multicolumn{2}{|c|}{ Frequency (Number of students) } \\
\hline & General Mathematics & Social Science \\
\hline $0-10$ & 13 & 00 \\
\hline $10-20$ & 10 & 01 \\
\hline $20-30$ & 30 & 18 \\
\hline $30-40$ & 19 & 25 \\
\hline $40-50$ & 07 & 14 \\
\hline $50-60$ & 01 & 05 \\
\hline $60-70$ & 01 & 10 \\
\hline $70-80$ & 01 & 05 \\
\hline Tot: & 82 & 78 \\
\hline
\end{tabular}

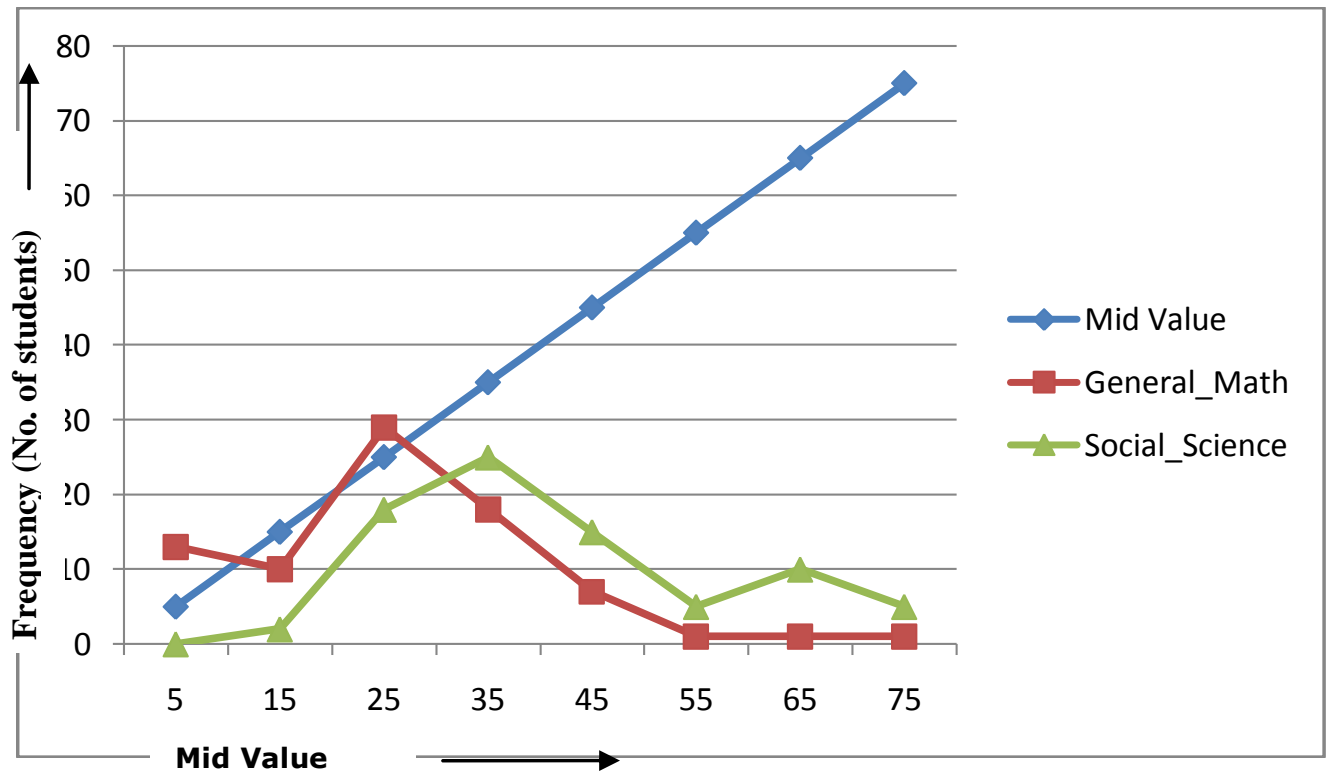

Observations:-

The above statistical data shows that less Number of Students obtain $60 \%$ or above marks in General Mathematics in comparison to Social Science. The number of Students getting $60 \%$ or above in Mathematics in the Annual Examination in 2015 is 03 in Class IX comparison to Social Science where the number is 8. In Class X also the number of Students getting 60\% and above marks in Mathematics is only 02 (Two) and in Social Science the number of such students is 07 (seven). In 2016 also the number of students getting 60\% and above marks in Mathematics in Class IX is only 02 (Two) where as in Social Science the number is 15 (fifteen). The result of the observations is as follows -

\begin{tabular}{|l|c|c|c|c|c|c|c|c|}
\hline \multirow{2}{*}{$\begin{array}{l}\text { Percentage } \\
\text { Of Marks }\end{array}$} & \multicolumn{4}{|c|}{ In 2015 } & \multicolumn{4}{c|}{ In 2016 } \\
\cline { 2 - 9 } & $\begin{array}{c}\text { No Of Students Of } \\
\text { Class Ix }\end{array}$ & \multicolumn{2}{c|}{$\begin{array}{c}\text { No Of Students Of } \\
\text { Class X }\end{array}$} & \multicolumn{2}{c|}{$\begin{array}{c}\text { No Of Students Of } \\
\text { Class Ix }\end{array}$} & $\begin{array}{c}\text { No Of Students Of } \\
\text { Class X }\end{array}$ \\
\hline Subjects & G. Math & $\begin{array}{l}\text { Social } \\
\text { Science }\end{array}$ & G. Math & $\begin{array}{l}\text { Social } \\
\text { Science }\end{array}$ & G. Math & $\begin{array}{l}\text { Social } \\
\text { Science }\end{array}$ & G. Math & $\begin{array}{l}\text { Social } \\
\text { Science }\end{array}$ \\
\hline Below 30\% & 48 & 17 & 26 & 06 & 47 & 12 & 19 & 02 \\
\hline $\begin{array}{l}50 \% \text { And } \\
\text { Above }\end{array}$ & 15 & 41 & 12 & 23 & 10 & 35 & 11 & 30 \\
\hline $\begin{array}{l}\text { 60\% And } \\
\text { Above }\end{array}$ & 05 & 20 & 05 & 15 & 06 & 24 & 07 & 27 \\
\hline $\begin{array}{l}\text { 80\% And } \\
\text { Above }\end{array}$ & 02 & 08 & 02 & 07 & 02 & 15 & 02 & 05 \\
\hline
\end{tabular}




\section{Causes for weakness in Mathematics:-}

According to my observation, some of the causes for weakness in Mathematics in comparison to other Subjects are -

1. Theory part of Mathematics is itself not interesting and some of the topics can also be not represented by different models or diagrams.

2. In lower primary as well as upper primary classes the basic Concepts of different mathematical terms have not been explained in easy language and with sufficient diagrams in text books.

3. There is Lack of sufficient elaborate explanations of different mathematical terms and definitions in Text books.

4. Insufficient Equipments or instruments for Practical Classes in Mathematics in the Senior Secondary Schools

\section{Remedial Suggestions:-}

From my own experience, I had innovated myself some methods to grow interest in Mathematics -

1. In lower and upper primary classes the basic concepts can be explained with the help of different games among the students.

2. Geometric concepts can be explained with the help of different models and Geo-boards.

3. Difficult problems of Set theory can be made easy to understand with the help of models of Venn diagrams of different set operations

4. To make the subject interesting audio - video classes, different workshops and seminars should be frequently arranged in the schools.

\section{References:-}

1. Charts of marks obtained by the students of Class - IX and X of the School - A in 2015 and 2016.

2. "How children learn" written by John Halt.

3. "How Children Succeed, girl, curiosity..... written by Paul Tough.

\section{From:-}

Debajit Mitra

(Mathematics Educator)

Doom Dooma Bangiya Vidyalaya

Doom Dooma, Dist. Tinsukia

Assam, India

Contact No.: (+91)8404047539

E-mail Id: debajitmitra.dm@gmail.com 